\title{
RAFAEL BALLESTEROS Y LOS VISLUMBRES DEL VELO
}

\section{DE UNA TRAYECTORIA LITERARIA}

Rafael Ballesteros (Málaga, 1938) es autor de una diversificada obra literaria que se ha prodigado sobre todo en poesía, pero que también se ha extendido a la narrativa y al teatro. Como filólogo cuenta asimismo con una bibliografía muy estimable, centrada especialmente en el estudio de diversos poetas españoles del siglo xx, entre ellos José Moreno Villa, Blas de Otero y Ricardo Molina. Sin embargo, la modalidad que más le identifica como escritor es la poética, siendo la veta más temprana de su pluma, y la más sostenida.

En la segunda mitad de los sesenta comenzaron las entregas poéticas del escritor malagueño, entre las que destacan, en esos años, Las contracifras, conjunto aparecido en 1969. Publicado el libro Turpa en 1972, el único que saldría en esa década, los ochenta iban a ofrecer varias comparecencias editoriales, pues el poeta dio a la estampa obras que se fueron sucediendo, entre las cuales merecen resaltarse Jacinto (Primera versión de la primera parte) (1983), La cava y Séptimas de Ammán, las dos fechadas en 1984, Numeraria (1986) y De Crisides a Jacinto (1987), creación con la que culminaban sus cuatro lustros primeros de singladura lírica, recogidos y prologados por mi mismo en el volumen Poesía (1969-1989), que vio la luz en Málaga en 1995.

Cuando se editó este corpus en el que se reunían los libros que salieron durante los sesenta y setenta, Rafael Ballesteros ya había publicado un conjuntos más, Testamenta (1991), que avanza en la consolidación de un ciclo nuevo en su obra. Al igual que en los ochenta, la última década del siglo sería muy nutrida en libros editados, incrementando la serie titulada Jacinto con dos entregas más, y con los paréntesis especificadores respectivos de (Primera versión de la II parte) (1997) y (Primera versión de la III parte) (1998). A este par de obras les antecedió el relato en prosa meditativa y con atisbos poéticos De los poderosos (1996) y la colección de pensamientos y aforismos que se integraron en Fernando de Rojas acostado sobre su propia mano, escritos en dos series, la que se imprime en 1999, y la que saldría en 2002, ya en los albores del nuevo milenio.

En 2002 iba a completarse también Jacinto, porque así lo señala su paréntesis informativo: (Primera versión de la IV y última parte), culminándose un proyecto poético 
vastísimo que se aproxima a los dos mil versos. Pero ya un año antes había dejado de exclusivizar Rafael Ballesteros su creatividad literaria en la poesía sensu strictu, porque en 2001 escribe el libreto de Amor pelirrojo, una ópera electrónica para cuatro voces solistas, un coro de voces blancas y un trío de figurantes. Una de las vertientes de su obra poética, la dialógica, reclamaba espacio propio en su escritura para plasmarse en una pieza de naturaleza teatral, y Ballesteros se lo abrió.

En 2003 publicó el poeta el conjunto lírico Los dominios de la emoción y en los años siguientes dedicará su pluma de manera muy intensa al relato y a la novela, como lo acreditan cinco obras que se editaron en un período de cuatro años: La imparcialidad del viento (2004), Huerto místico (2005), Amor de mar (2005), Los últimos días de Thomas de Quincey (2006), y Cuentos americanos (2006). Y no tardaría en aparecer una sexta entrega narrativa, La muerte tiene la cara azul (2009). Es éste un muy amplio relato de recreación histórica -se dilata desde 1830 a comienzos del posfranquismo- en el que su autor estuvo trabajando desde tres lustros antes, y al que se concedió en 2010 el Premio de la Crítica de Andalucía.

El libro de poemas Nadando por el fuego fue estampado en 2012 en una edición francesa de reducidísima tirada, y no venal, y por ende puede considerarse que esta obra no se edita hasta que se incorpora al volumen preparado por Juan José Lanz que en 2015 recoge, salvo las cuatro versiones de Jacinto, su Poesía (1990-2010). Entre uno y otro años iba a reaparecer otra vez la vena escénica del escritor malagueño en una escritura inspirada en su alter ego Fernando de Rojas, y de sesgo híbrido, pero ya más decididamente teatral, como se declara en el paréntesis que sigue a su título: Contramansedumbre (Fernando de Rojas y el Inquisidor. Poema para representar).

\section{RETORNOS DEL EXTREMO}

Con anterioridad a La cava y Séptimas de Ammán, creaciones publicadas respectivamente en 1984 y 1985, la escritura literaria ballesteriana había emprendido y desarrollado un proceso de hermetización continuo que se apoyaba en rupturismos múltiples, que tuvo un ápice en Turpa y llegó a extremarse en la entrega primera de Jacinto, que data de 1983. Pero desde La cava el poeta comenzaría un camino deconstructivo de la opacidad y fue avanzando hacia una poética cada vez menos oscura que permitiese apreciar mejor sus logros estéticos y acceder a sus meditaciones cavilosas.

Esa poética se consolida en Testamenta, refrendándola Los dominios de la emoción y Nadando por el fuego, libros del nuevo milenio que reflejan, desde la tensión lírica y dialógica consustanciales del autor, el equilibrio entre la sustancia biográfica, las reflexiones participadas y la exigencia literaria rigurosa. Estas vertientes se intersectan 
y se dejan atisbar a los lectores mediante perfiles de vida propia que se reconocen, pensamientos e interrogaciones legibles, y trazos plásticos e imaginísticos de muy conseguido valor estético.

\section{RETAZOS Y JIRONES DE VIDA}

Sesgos vividos por el autor textual son reconocibles aquí y allá en no pocos poemas de la entera obra ballesteriana, y por supuesto en Testamenta, donde el entorno familiar se hace muy evidente en su diálogo con los hijos que han de heredarle su palabra transida de avatares vitales y su palabra literaria, y en el recuerdo elegíaco a los desaparecidos, a cuya remembranza volverá en páginas líricas de Los dominios de la emoción. Pero hay también otros desaparecidos más íntimos, sus adolescencias, y las etapas que las sucedieron hasta el momento de evocarlas.

En De los poderosos es innegable que repercute la experiencia de Rafael Ballesteros en las esferas del poder durante los lustros en que se dedicó a la actividad política institucional como diputado por el PSOE en el Congreso, cámara en la que fue durante varias legislaturas presidente de su comisión de cultura. Pero esa experiencia, como parece obvio, ha sido por completo transformada, travestida, sin que puedan reconocerse lugares, acontecimientos ni personas.

En Los dominios de la emoción, el tríptico «Sinfonía en tres tiempos. Opus LXXIV» se dedica expresamente a sus amigos de Barcelona a cuyo lado hubo de arrostrar la represión franquista en los acabamientos de la dictadura, toda vez que un episodio biográfico de la misma, su encarcelamiento en diciembre de 1974, se rememora y poetiza en esos versos en los que se trenza la historia personal con la colectiva de la lucha por la recuperación de la democracia. Y en Nadando por el fuego, y por poner un último ejemplo, cumple que apuntemos al respecto al texto inspirado en la catedral de León, ciudad en la que se demoró con complacencia más de una vez, de lo que puedo dar fe.

Y atravesando su obra la plasmación evocativa de distintas vivencias hondas en relaciones eróticas tan apasionadas como caleidoscópicas, de la ética y el desafuero en los predios de la actividad política, de la constante interrogación por el sentido de la poesía y de la suya, de la dialéctica entre lo trascendente y lo solo inmanente, y siempre el reflexivo indagar, preguntándose qué haya sido y sea vivir para él y qué suponga la muerte para el ser humano, para sí mismo y para su propia escritura.

\section{Palabra de apasionados Sentidos}

De los contenidos que se cifran en la obra poética de este escritor andaluz uno diría que reflejan un nihilismo radical, aunque selectivo. Radical porque se niega que 
nada se sepa de veras ni que pueda saberse con certeza alguna, resonando en ese parecer el lejanísimo Nihil scitur socrático, aunque socavado en su rotundidad por algunos barruntos sobre qué pueda ser la vida humana y la escritura.

Esta tesis afecta de manera muy notoria a la esfera de lo sagrado, desestimada a favor de la materia, de ahí que lo sensitivo, lo táctil, y lo palpable se erijan en el único modo de acercarse a un conocimiento menos falso y trucado de las cosas. Son lo menos incierto en un mundo incierto. En cualquier caso, la duda será siempre lo más riguroso, y por ende en la poesía ballesteriana arrecian las interrogaciones, planteándose el dicente constantes preguntas sin tregua a las que nadie responde, en flagrante contraste con esas preguntas tramposas y metafísicas de las que se concluyen falsedades en materia cosmovisionaria que se presentan como verdad pulpital, cuando no política, que ha de seguirse.

El amor se inscribe en la aventura de autoconocerse por medio de una perlúcida pasión paradójicamente distante, y de su goce apasionado cabe predicar, si bien como metáfora repristinada, que «salva» a través de la alegría y las satisfacciones placenteras disfrutadas merced a los sentidos. La pasión tiene en el eros un campo y un horizonte fértiles, aunque tampoco se libra del rasero segador que abre la puesta a la duda sobre si el hablante la defiende para agarrarse al menos a un humo ardiendo.

La consistencia de la identidad se concibe bajo mínimos, siendo un proceso inestable y continuado de forja de la misma que no superará nunca su endeblez y su nadería consustancial, amén de que en uno se comprende asimismo la madeja laberíntica de otros. El yo se va construyendo en una construcción que solo acaba con la muerte. La escritura, y la poética en concreto, no comporta ulterioridad de ningún tipo como no sea su propia evidencia textual, una evidencia que no engaña cuando se entiende como fin en sí misma. No hay una teología de la literatura, porque tampoco la hay en la vida.

Como la literatura no se trasciende a sí misma, y en modo alguno constituye una creación que «salva» a quien la crea, es una de las principales excepciones del nihilismo ballesteriano, y que nos permitió calificarlo como selectivo. Hay otras, porque el principio socrático de que nada se sabe se matizará con aquel de los epicúreos según el cual nada hay al otro lado de la realidad material. Los principios éticos que se fueron conformando a lo largo de los años escaparían también del arrasador alcance dubitativo.

\section{LA DIFUMINACIÓN LITERARIA}

Las que acabamos de sintetizar son las constataciones que, como lector, extraería a partir de las vislumbres que atisbo en los versos de Rafael Ballesteros, las cuales se 
dejan entrever un tanto, y de vez en vez, no sin que el velo poético de su obra creativa las haya difuminado con los procedimientos literarios de distinto signo de los que ha ido valiéndose el escritor. Me limitaré a enunciar algunos.

Aparte del enmascaramiento que supone el hecho mismo de que el dicente poemático no sea convalidable por el autor textual, Rafael Ballesteros se sirve de personajes distintos en cuyos labios pone sus especulaciones y sus hablas. Uno es el de Jacinto, que protagoniza el gigantesco poema en sucesivas versiones que lleva su nombre. El otro es el escritor del quince Fernando de Rojas, a cuyo pensamiento atribuye el suyo propio en las dos series aforísticas tituladas Fernando de Rojas acostado sobre su propia mano, y en la pieza escénica Contramansedumbre.

Jacinto representa al joven que todo lo tiene que ir descubriendo. Rojas sería el hombre curtido que, en virtud de la experiencia y de la meditación, ya ha llegado a algunas reflexiones definitvas sobre las cosas más fundamentales. Ambos roles se conjugan en De Crisides a Jacinto y en De los poderosos, donde aparecen el filósofo anciano Crisides, y el joven Jacinto, aquél alertándole acerca de sofismas de poderes manipuladores y sobre los vaivenes del existir. Son éstos los personajes sin duda relevantes en quienes se subsumen principalmente las perspectivas ballesterianas.

Sin embargo, las voces múltiples del autor también transparecen en otros personajes en escrituras dialogadas como Jacinto y Contramansedumbre, o bien se conforman en contraste con entes amonestadores, como el anidado en una conciencia, de raíz bíblica, que vaticina la perdición del hablante, o el Satanás que, de ese mismo origen, le incita a persistir indagando más allá de un pensamiento heredado que le inculcó supuestas verdades presentadas como racionales y creencias religiosas adoctrinadas como guía conductual y trascendente.

Otro medio llamativo en la poética de Rafael Ballesteros que la identifica de tal modo que su palabra se distingue con evidencia de cualesquiera otras, consiste en sus peculiarísimos usos idiomáticos, unos usos que, si bien no impiden la intelección, sí la dificultan un tanto a la vez que la potencian en aras de crear un registro lingüístico propio reconocible. Arcaísmos del castellano conviven en su obra con neologismos, apartándose así el poeta de un habla normativa común, y no con vistas a remarcar un prurito singularizador, sino para exprimir el lenguaje rebuscando sentidos no hollados en la expresividad. El nochearniego del Arcipreste resuena en el seno de la nueva palabra nocturniego, por poner una ilustración.

Pero las técnicas idiomáticas modificadoras son muy variadas, y entre ellas sobresalen y nos sorprenden hallazgos tan felices como "dudivoso», que tan bien apunta a una de las claves de su universo poético, la de la interrogación sin tregua, o la invención del verbo «manuar», que asimismo remite a ellas, al hacer referencia a 
espectros de lo palpable. En ese dominio de lo táctil creará el verbo «bocarse», pues si en la entrega -acaso mejor refriega- erótica puede decirse «tócame», también puede nacer de la experiencia el decir, como en el poema «Aquella amánte romántica», de Los dominios de la emoción, «Bócame./ Trágame...».

Una amalgama estética neorromántica, neoanguardista de cuño vallejiano, neosurrealista, y neobarroca, se da cita en la obra poética de Rafael Ballesteros. Tales registros contribuyen a crear en los lectores menos atentos y demorados una sensación de encontrarse ante páginas de una opacidad por momentos aguda y con propósito de mostrarse apenas accesible. Empero, las prácticas literarias del poeta deslizan indicios y abren vías que permiten aproximarse a las claves de su singular universo literario, un universo en el que la mente y la palabra no cesan de pretender adentrarse en lo hondo, pero desestimando consagrarse a la indagación en lo que se presume oculto. Esa es la punta del puzzle mental, lírico y de expresión que se intersecta y vislumbro en la obra literaria ballesteriana.

José María Balcells Doménech 